\title{
Variability in the Deep Western Boundary Current in the equatorial Atlantic at $44^{\circ} \mathrm{W}$
}

\author{
Lothar Stramma and Monika Rhein ${ }^{1}$ \\ Institut für Meereskunde, Kiel, Germany.
}

\begin{abstract}
The variability of the North Atlantic Deep Water (NADW) was studied by ten hydrographic repeat sections taken along $44^{\circ} \mathrm{W}$ off Brazil between September 1989 and March 1994. This data set allowed for the first time to describe the seasonal signal in the Deep Western Boundary Current at the equator from hydrographic data. Annual and semiannual layer thickness modulations were observed similar to such signals in transport time series, however with a time lag of 2 months. A comparison of the interannual variability of the Labrador Sea Water component of the NADW at $44^{\circ} \mathrm{W}$ at the equator with the formation region indicated a time lag of 13 to 17 years. The effective spreading velocities in the Labrador Sea Water are in the range 2 to $5 \mathrm{cms}^{-1}$ for the tropical Atlantic Ocean.
\end{abstract}

\section{Introduction}

Recently it was observed, that annual as well as longterm variability are present in the Deep Western Boundary Current in the tropical Atlantic. The analysis of moorings placed in the Deep Western Boundary Current (DWBC) at $44^{\circ} \mathrm{W}$ for three years resulted in a definite seasonal cycle, ranging from less than $7 \mathrm{~Sv}$ during September/October to about $25 \mathrm{~Sv}$ during January/February. Annual and semiannual transport harmonics had similar amplitudes, at about $6 \mathrm{~Sv}$ each, and together they explained about two third of the total transport variability [Fischer and Schott, 1997]. Andrie et al. [1999] suggest that there is a DWBC recirculation offshore of the DWBC whose origin appears variable, however from 3 cruises they could not proove semiannual DWBC variability.

Curry et al. [1998] described that the deep ocean is influenced by long-term variability and tracked signals from the Labrador Basin to Bermuda with a six year transit time. Vaughan and Molinari [1997] used a ten-year (1984-1993) time series of repeat hydrographic sections at $26.5^{\circ} \mathrm{N}$ (Figure 1) from offshore Abaco Island, the Bahamas, to investigate variability for four layers of the DWBC. The effective spreading time from the Labrador Sea to $26.5^{\circ} \mathrm{N}$ was observed by Molinari et al. [1998] with 10 years.

Here we use a series of hydrographic repeat sections and for the first time it was possible to study variability in the deep water on seasonal to inter-annual time scales and to estimate transfer times of Labrador Sea Water from the source region to the tropical Atlantic. This investigation

\footnotetext{
${ }^{1}$ Now at Universität Bremen, Bremen, Germany.
}

Copyright 2001 by the American Geophysical Union.

Paper number 2000GL011777.

0094-8276/01/2000GL011777\$05.00 completes previous descriptions of the tropical Atlantic from mooring and tracer measurements [Rhein et al., 1995; Fischer and Schott 1997].

\section{The Data and Water Masses}

The ten CTD repeat sections (Table 1) along $44^{\circ} \mathrm{W}$ (Figure 1) north of the Brazilian shelf break were taken between 1989 and 1994 from two groups from Miami, USA (generously provided by R.L. Molinari, Miami) and from Kiel, Germany. Accuracies of the hydrographic measurements were on the order of $0.002^{\circ} \mathrm{C}$ in temperature and 0.003 in salinity (e.g. Rhein et al. [1998]). There seemed to be a a 0.002 salinity offset between some of the Kiel and Miami cruises which is however not relevant for the results presented here as salinities are not compared directly.

The NADW is separated into four layers using the boundaries selected by Rhein et al. [1995] based on the CFC and parameter distributions in the tropical Atlantic. In the shallowest part of the upper NADW a salinity maximum bounded by the isopycnals $\sigma_{1}=32.15(\sim 1200 \mathrm{~m})$ and $\sigma_{2}$ $=36.94(\sim 1900 \mathrm{~m})$ exists which is correlated to elevated concentrations of tritium and CFC all along the western boundary (e.g. [Fine and Molinari, 1988; Molinari et al., 1992]). This water mass was named upper Labrador Sea Water (uLSW) by Pickart [1992]. The Labrador Sea Water (LSW) formed in the central Labrador Sea shows in the tropics a lower CFC signal than the uLSW above and is identified by an oxygen maximum. The lower boundary is at about $2400 \mathrm{~m}$ at the isopycnal $\sigma_{2}=37.00$.

Within the Lower NADW (LNADW) a CFC minimum is located above a CFC maximum. Hence LNADW is separated in an upper core with the CFC minimum originating from Charlie Gibbs Fracture Zone Water (CGFZW) bounded by the isopycnal $\sigma_{4}=45.83$ at about $3450 \mathrm{~m}$ to the Overflow LNADW (OLNADW) below with the CFC maximum and an oxygen maximum originating from the Den-

Table 1. Dates and ship names for the $44^{\circ} \mathrm{W}$ sections.

\begin{tabular}{ll}
\hline Date & Ship \\
\hline Sep. 3 - 6, 1989 & RV BALDRIGE \\
Feb. 11 - 15, 1990 & RV MT. MITCHELL \\
Sep. 27 - Oct. 1, 1990 & RV BALDRIGE \\
Oct. 6 - 13, 1990 & RV METEOR (M14) \\
Jan. 23 - 26, 1991 & RV BALDRIGE \\
May. 24 - 27, 1991 & RV METEOR (M16) \\
June 30 - Jul. 3,1991 & RV BALDRIGE \\
Sep. 7 - 11, 1991 & RV BALDRIGE \\
Oct. 27 - 31, 1992 & RV METEOR (M22) \\
Feb.28 - Mar. 5, 1994 & RV METEOR (M27) \\
\hline
\end{tabular}




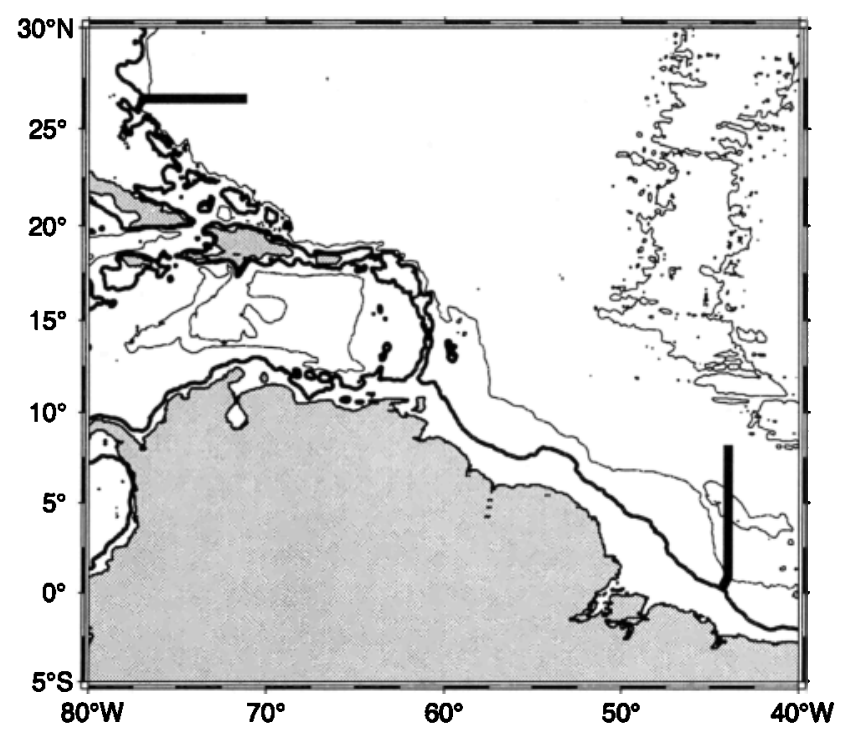

Figure 1. Locations of hydrographic sections at $44^{\circ} \mathrm{W}$ and at $26.5^{\circ} \mathrm{N}$ used by Molinari et al. [1998] (thick lines). The 1000 dbar contour (medium thick line) bounding the DWBC and the 4000 dbar contour (thin line) are included.

mark Strait Overflow Water. The isopycnal $\sigma_{4}=45.90$ separates the OLNADW from the northward spreading Antarctic Bottom Water (AABW).

\section{Results}

The mooring results at $44^{\circ} \mathrm{W}$ [Fischer and Schott, 1997] showed substantial annual and semiannual contributions (Figure 2). Based on this observation, the hydrographic measurements were investigated for the low frequency variability by harmonic analysis of the annual and semiannual signal. A part of the CTD measurements were not done to the bottom, hence the amount of data for the OLNADW was too sparse for a seasonal investigation, and was not analysed here.

\subsection{Semiannual and Annual Variability}

In Figure 2 the harmonic analysis time series of the LSWthickness between the isopycnal boundaries described before between 0 and $1^{\circ} \mathrm{N}$ is compared to the $44^{\circ} \mathrm{W}$ mooring transport time series of two deployment periods. From the hydrographic data alone a semiannual as well as an annual signal as in the mooring records of Fischer and Schott [1997] can be described. The extrema in LSW thickness follow the extrema in southward transport [Fischer and Schott, 1997] about two months later with a phase error of 40 days. During the two periods with transports larger than the southward mean of $13 \mathrm{~Sv}$ (marked I and II in Figure 2), the thickness of the LSW increases, and the thickness decreases during periods with lower transports. The velocity core of the DWBC is located in the LSW layer, hence at times of stronger transport the LSW layer in and to the north of the DWBC widens and consequently fills a LSW reservoir, while the layers above and below reduce their vertical extent (Figure 3). Similarly, from time series of temperature at the equator Hall et al. [1997] reported that the LNADW/AABW transition layer rises and falls in synchrony with the quasi-annual AABW transport cycle with uplifted transition layer during strong AABW transport periods. In the $2^{\circ}$ to $6^{\circ} \mathrm{N}$ band, the uLSW thickness is opposite to the 0 to $2^{\circ} \mathrm{N}$ one. In the DWBC the highest velocities are found in the LSW layer, and at times the LSW thickness changes, the uLSW and CGFZW layer thicknesses in the 0 to $2^{\circ} \mathrm{N}$ band are in antiphase probably by water exchange especially for the uLSW with the region north of $2^{\circ} \mathrm{N}$.

The annual cycle for the thickness of the uLSW-, LSWand CGFZW layers indicate two maxima and minima of the annual and semiannual signal of the DWBC at 0 to $1^{\circ} \mathrm{N}$. They are found also in the Guiana Basin north of $1^{\circ} \mathrm{N}$ (Figure 3) although the $\mathbf{1 0}$ sections are still too sparse to resolve all extrema. An increase or decrease in the LSW layer is accompanied by a reversed amplitude either in the uLSW or the CGFZW layers or in both layers in the band 0 to $2^{\circ} \mathrm{N}$. The variance accounted for both the annual and the semiannual signal is about $50 \%$ between 0 and $1^{\circ} \mathrm{N}$ and up to $80 \%$ at $2^{\circ} \mathrm{N}$. This high variance explained by the annual and semiannual signal and the similarities of the mooring data convinces us, that despite the fact that the minima and maxima are placed at times without measurements, the data represent well the decrease and increase of the layer thickness.

\subsection{The LSW Spreading Signal}

Rhein et al. [1996] applied a boxmodel tuned by tracer distributions using the CFC dating methods and taking into account selfmixing in the DWBC and mixing with surrounding water masses. They calculated that the maximum mean spreading velocity of deep water masses in the DWBC from the source regions in the subpolar North Atlantic to the equator is $5 \mathrm{cms}^{-1}$. From CFC and tritium distributions at $44^{\circ} \mathrm{W}, 35^{\circ} \mathrm{W}, 5^{\circ} \mathrm{S}$ and $10^{\circ} \mathrm{S}$ off the Brazilian shelf of the upper layer of the DWBC, Rhein et al., [1998] concluded that the temporal tracer change is due to the arrival of 'younger' water, however disturbed by mixing and different spreading pathways and estimated a ventilation age of 20 years at $5^{\circ} \mathrm{S}$. While these authors used CFC apparent ages Molinari et al.

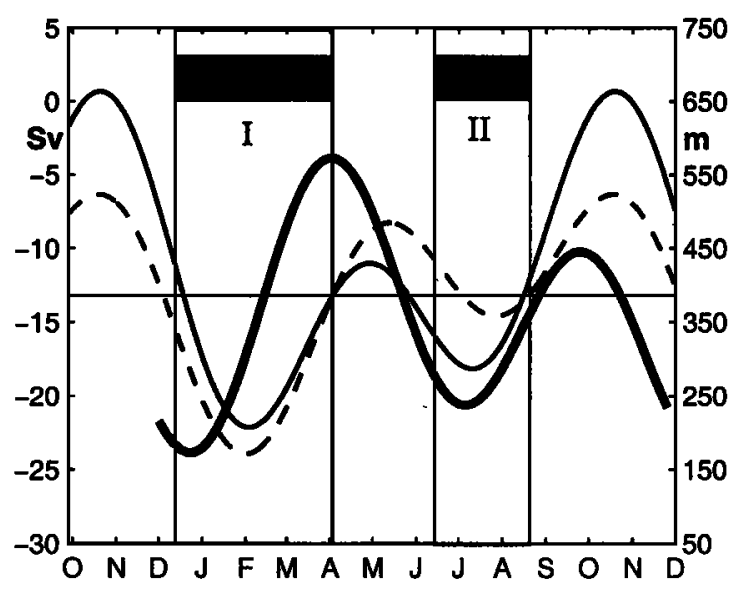

Figure 2. Comparison of the DWBC transport harmonics (in Sv) from 1000 to $3100 \mathrm{~m}$ from the moorings [Fischer and Schott, 1997] for 1990/91 (dashed line), 1992/93 (thin solid line) and the annual cycle of the LSW thickness (in $\mathrm{m}$ ) between 0 and $1^{\circ} \mathrm{N}$ (thick solid line) at $44^{\circ} \mathrm{W}$. The two periods I and II mark the times, when the transport is larger than the mean transport of $13 \mathrm{~Sv}$. 

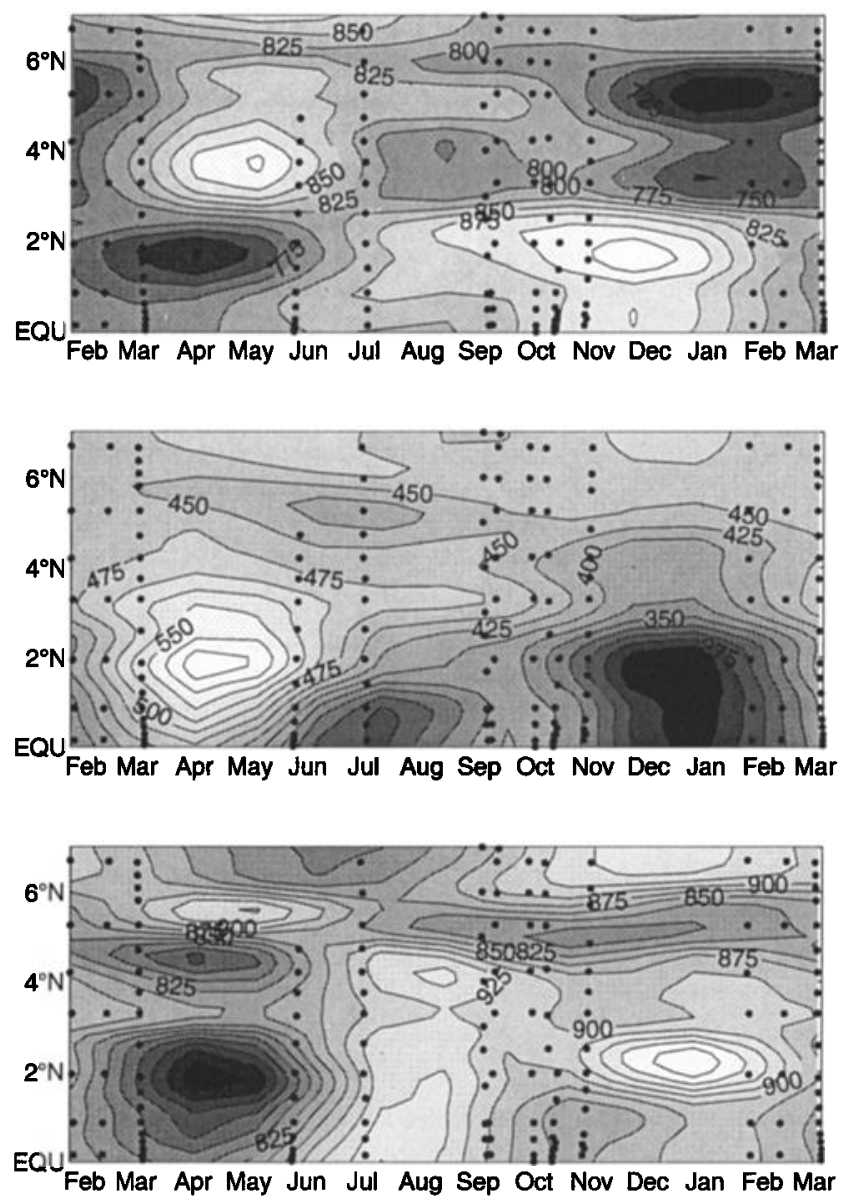

Figure 3. Harmonic analysis of the thickness (in dbar) with a contour interval of $25 \mathrm{dbar}$ for the uLSW (top), the LSW (center) and the CGFZW (bottom) between the isopycnals defined in the text. Dots indicate the CTD-stations.

[1998] used the density surface $\sigma_{1.5}=34.67$ in the LSW at $26.5^{\circ} \mathrm{N}$ as a dating tool to estimate the time lag of 10 years between the formation region and $26.5^{\circ} \mathrm{N}$ with an effective spreading rate of $2-2.5 \mathrm{cms}^{-1}$. As the tracer distributions are not only influenced by advection but also by turbulent mixing on different spatial and temporal scales the direct velocity observations overestimate the net lagrangian parcel motion. Much higher velocities were observed in direct measurements in the core of the DWBC, like instantaneous along-boundary velocities often above $25 \mathrm{cms}^{-1}$ in the SOFAR floats of Richardson and Fratantoni [1999] or a mean velocity from a mooring at $2000 \mathrm{~m}$ at $44^{\circ} \mathrm{W}$ of up to 40 $\mathrm{cms}^{-1}$ [Fischer and Schott, 1997]. Although our time series at the equator is relatively short, a test was made to compare the temperature and salinity on the density surface $\sigma_{1.5}=34.67$ to the LSW time series from the central Labrador Sea [from Lazier used in: Sy et al., 1997].

At $44^{\circ} \mathrm{W}$ the $\mathrm{LSW}$ should be 0.4 to $0.6^{\circ} \mathrm{C}$ warmer and 0.12 to 0.15 more saline than in the LSW formation region, according to maps on the density surface $\sigma_{1.5}=34.67$ from the hydrobase data set compiled by R. Curry ([Curry, 1996]). Although the data within the hydrobase dataset include variability, we expect that it represents a smoothed climatological mean value and reduced the salinity and temperature observations at $44^{\circ} \mathrm{W}$ by these values in Figure 4 . Hence, the temperature and salinity range derived from the hydrobase dataset should represent the uncertainty for the method used. We use the velocity of $5 \mathrm{cms}^{-1}$ of Rhein et al., [1996] as upper bound for the region south of $26.5^{\circ} \mathrm{N}$ which leads to a spreading time of 3 years from $26.5^{\circ} \mathrm{N}$ to the equator at $44^{\circ} \mathrm{W}$. Combined with the 10 years from the LSW formation region to $26.5^{\circ} \mathrm{N}$ ([Molinari et al., 1998]) the $44^{\circ} \mathrm{W}$ observations have to be shifted back in time by at least 13 years (line in February 1981 in Figure 4). The records of high potential temperature and salinity in the Labrador Sea before 1972 show that the possible maximum shift in time for $44^{\circ} \mathrm{W}$ data is 17 years. Indication for best agreement was found with a 15 years time lag to the formation region (Figure 4) as it reproduces in 1991 at the equator the slightly intensifiec 1976 LSW formation.

The direct path following the contours of the $1000 \mathrm{dbar}$ depth between $26.5^{\circ} \mathrm{N}$ and $44^{\circ} \mathrm{W}$ at the equator is about $4800 \mathrm{~km}$. For the 15 years spreading time the time lag of 5 years from $26.5^{\circ} \mathrm{N}$ to $44^{\circ} \mathrm{W}$ results in a mean spreading velocity of the signal within the DWBC of $3.0 \mathrm{cms}^{-1}$. The maximum possible time shift of 17 years would lead to a spreading velocity of $2.2 \mathrm{cms}^{-1}$ south of $26.5^{\circ} \mathrm{N}$, still a realistic and reasonable velocity. Hence the short hydrographic time series at $44^{\circ} \mathrm{W}$ at the equator confirm the earlier estimates of effective DWBC spreading velocities in the LSW in the range 2 to $5 \mathrm{cms}^{-1}$ also for the tropical Atlantic Ocean.

\section{Final Remarks}

Perhaps the most important issue regarding the annual and long-term fluctuations is their potential impact on long term studies. Given that large variability exists, climate changes investigated by repeated sections some years apart
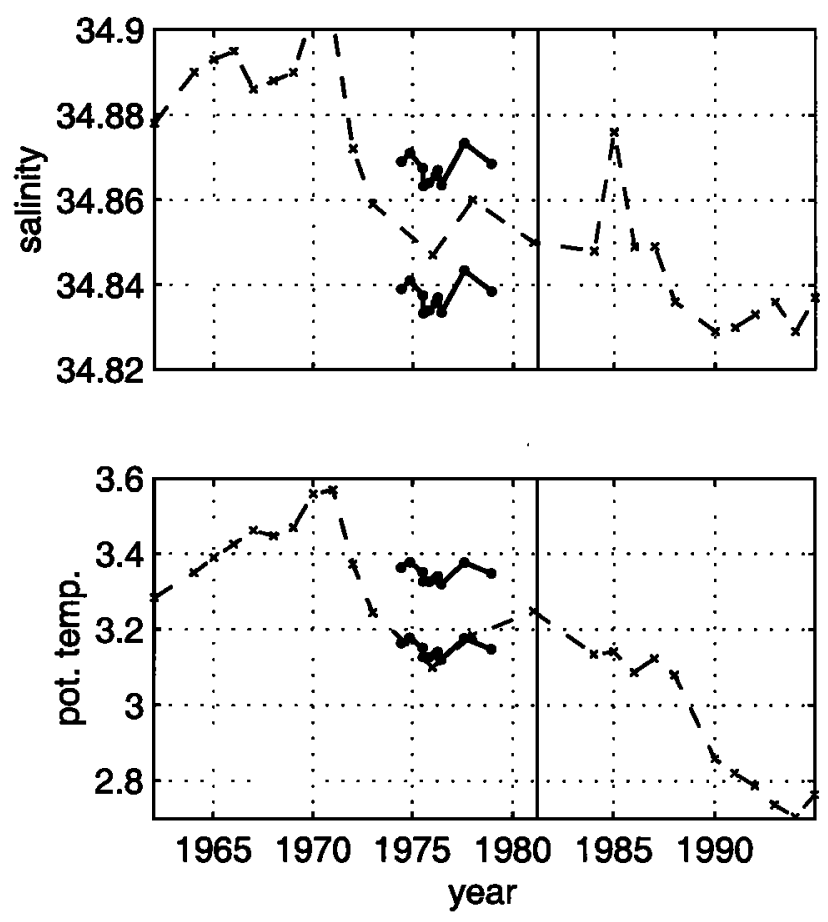

Figure 4. Time series of salinity and potential temperature of LSW from the central Labrador Sea [from Lazier used in: $S y$ et al., 1997] (crosses with dashed line) and salinity and potential temperature on $\sigma_{1.5}=34.67$ at $44^{\circ} \mathrm{W} 0$ to $1^{\circ} \mathrm{N}$ shifted 15 years backwards in time and reduced by 0.12 and 0.15 in salinity and 0.4 and $0.6^{\circ} \mathrm{C}$ in temperature (dots with solid line). Vertical line is estimate of minimum travel time (see text). 
might be obscured by this variability. The comparison of the arrival of LSW signals at the equator with the formation region reproduces reasonable transfer time estimates. For the first time the data base of ten hydrographic sections was large enough to investigate semiannual and annual variability at $44^{\circ} \mathrm{W}$ in the DWBC and north of it.

Acknowledgments. Support was given by the Bundesministerium für Bildung, Wissenschaft, Forschung and Technologie, Bonn under grant 03F0176A. R. L. Molinari, Miami, generously provided the Miami-group CTD data used here and provided many helpful comments. A large amount of the computer work and figure composing was done by F. Morsdorf and many helpful comments were given by J. Fischer.

\section{References}

Andrie, C., J.F. Ternon, B. Bourles, Y. Gouriou, and C. Oudot, 1999: Tracer distributions and deep circulation in the western tropical Atlantic during CITHER 1 and ETAMBOT cruises, 1993-1996, J. Geophys. Res., 104 21,195-21,215, 1999.

Curry, R.G., 1996: HydroBase: a database and tools for climatologic analysis, Tech. Rep. WHOI-96-01, 44 pp., Woods Hole Oceanographic Institution, 1996.

Curry, R.G., M.S. McCartney, and T.M. Joyce, 1998: Oceanic transport of subpolar climate signals to mid-depth subtropical waters, Nature, 391, 575-577, 1998.

Fine, R.A., and R.L. Molinari, A continuous deep western boundary current between Abaco $\left(26.5^{\circ} \mathrm{N}\right)$ and Barbados $\left(13^{\circ} \mathrm{N}\right)$, Deep Sea Res., 35, 1441-1450, 1988.

Fischer, J., and F.A. Schott, Seasonal transport variability of the Deep Western Boundary Current in the equatorial Atlantic, $J$. Geophys. Res., 102, 27751-27769, 1997.

Hall, M.M., M. McCartney, and J.A. Whitehead, Antarctic Bottom Water flux in the equatorial western Atlantic, J. Phys. Oceanogr., 27, 1903-1926, 1997.

Molinari, R.L., R.A Fine, and E. Johns, The deep western boundary current in the tropical North Atlantic, Deep-Sea Res., 39, 1967-1984, 1992.
Molinari, R. L., R. A. Fine, W. D. Wilson, R. G. Curry, J. Abell, and M. S. McCartney, The arrival of recently formed Labrador Sea Water in the Deep Western Boundary Current at $26.5^{\circ} \mathrm{N}$, Geophys. Res. Lett., 25, 2249-2252, 1998.

Pickart, R.S., Water mass components of the North Atlantic deep western boundary current, Deep-Sea Res., 39, 1553-1572, 1992.

Rhein, M., O. Plähn, R. Bayer, L. Stramma, and M. Arnold, The temporal evolution of the tracer signal in the Deep Western Boundary Current, Tropical Atlantic, J. Geophys. Res., 103, 15,869-15,883, 1998.

Rhein, M., F. Schott, J. Fischer, U. Send, and L. Stramma, The deep water regime in the equatorial Atlantic, in The South Atlantic - Present and past circulation, edited by G. Wefer, W.H. Berger, G. Siedler and D.J. Webb, pp. 261-271, Springer Verlag Berlin, Heidelberg, 1996.

Rhein, M., L. Stramma, and U. Send, 1995: The Atlantic Deep Western Boundary Current: Water masses and transports near the equator, J. Geophys. Res., 100, 2441-2457, 1995.

Richardson, P.L., and D.M. Fratantoni, Float trajectories in the Deep Western Boundary Current and deep equatorial jets of the tropical Atlantic, Deep-Sea Res., II, 46, 305-333, 1999.

Sy, A., M. Rhein, J.R. Lazier, K.P. Koltermann, J. Meincke, A. Putzka, and M. Bersch, Surprisingly rapid spreading of newly formed intermediate waters across the North Atlantic Ocean, Nature, 386, 675-679, 1997.

Vaughan, S.L., and R.L. Molinari, Temperature and salinity variability in the Deep Western Boundary Current, J. Phys. Oceanogr., 27, 749-761, 1997.

L. Stramma, Institut für Meereskunde an der Universität Kiel, Düsternbrooker Weg 20, 24105 Kiel, Germany. (e-mail: lstramma@ifm.uni-kiel.de)

M. Rhein, Universität Bremen, Institut für Umweltphysik, Kufsteiner Strasse, 28359 Bremen, Germany. (e-mail: mrhein@physik.uni-bremen.de)

(Received June 16. 2000; revised October 24, 2000; accepted January 30, 2001.) 